\title{
Insight on population structure of the Chilean jack mackerel (Trachurus murphyi)
}

\author{
François Gerlotto ${ }^{1,2, a}$, Mariano GutiérReZ ${ }^{3}$ and Arnaud BerTRAND ${ }^{1}$ \\ 1 Institut de Recherche pour le Développement (IRD), UMR212 EME IFREMER/IRD/UM2, LMI DISCOH, Av. Jean Monnet, BP 171, \\ 34203 Sète Cedex, France \\ 2 Current address: Le Corfou, A1 rue de Clairval, 34170 Castelnau-le-Lez, France \\ 3 Universidad Nacional Federico Villareal, Facultad de Oceanografía, Pesquerías y Ciencias Alimentarias, Calle Francia 726, Miraflores, \\ Lima, Perú
}

Received 29 June 2012; Accepted 30 October 2012

\begin{abstract}
The Chilean jack mackerel (Trachurus murphyi) is one of the most important exploited fish populations in the world. Its area of distribution covers the sub-tropical waters of the South Pacific Ocean, from South America up to New Zealand and even Australia. It is subject to high variations in biomass, with annual world catches varying from less than 0.5 to almost 5 million tonnes. Management of this species and its fishery requires a correct understanding of the population structure. Although several hypotheses have been proposed, suggesting that there are up to four independent populations, genetic analysis indicates only a single population in the South Pacific Ocean. We consider the two most probable structures for this population: a "patchy population", where all the fish belong to a single population that expands and contracts depending on the biomass; and a metapopulation, where a source population creates several subpopulations that can remain independent during prolonged periods, depending on the environmental conditions. We studied the conditions for these hypotheses to represent reality, especially the demographic structure and existence of different spawning areas. Using knowledge obtained from fisheries and acoustic surveys, we show that if we apply their definitions strictly, neither of the two hypotheses can be fully rejected. Nevertheless, some particular spatial characteristics observed recently between the Peruvian and Centre-South Chilean parts of the distribution lead us to conclude that the metapopulation definition is likely to better describe the stock. The consequences of each population structure for fisheries management are listed, showing that the metapopulation hypothesis represents a safer definition for stock assessment. We conclude that T. murphyi can be described as a metapopulation, but also that the definitions proposed in the literature on metapopulations are not fully adapted to pelagic fish populations with a basin-scale distribution range, and suggests specific research that could be done in this field.
\end{abstract}

Keywords: Metapopulation / Patchy population / Fishery management / Trachurus murphyi / Southern Pacific Ocean

\section{Introduction}

The Chilean jack mackerel, Trachurus murphyi Nichols 1920, presents most of the common characteristics of Trachurus species: a rather long lifespan (around 15 years), maturity at around $30 \mathrm{~cm}$ (3 years) and predation on macrozooplankton and micronekton, especially copepods, euphausiids, and mesopelagic fish (Konchina 1981). However, it has the widest area of extension of this genus (Cardenas et al. 2005), being observed in the whole sub-tropical area of the South Pacific Ocean, from South America up to New Zealand, Australia (Serra 1991; Grechina 1998) and sometimes even the

a Corresponding author: francois.gerlotto@ird.fr southern subtropical areas of the Indian and Atlantic Oceans (Riede 2004; Nakamura et al. 1986). The T. murphyi fishery has been one of the largest in the world, with catches reaching almost 5 million tonnes in the year of highest production (1995). Since the late 1990s, T. murphyi has suffered a strong decrease in total catches, which dropped to close to 0.5 million tonnes: a decrease that likely reflects a similar decrease in abundance (see www.southpacificrfmo.org).

During high abundance periods, the overall biomass of T. murphyi was evaluated at around 20 million tonnes (Konchina and Pavlov 1999). Such biomass made this fish an essential target for the industrial fisheries. Biomass is dominated by a few strong cohorts, whose occurrence depends on environmental conditions (Konchina and Pavlov 1999). 


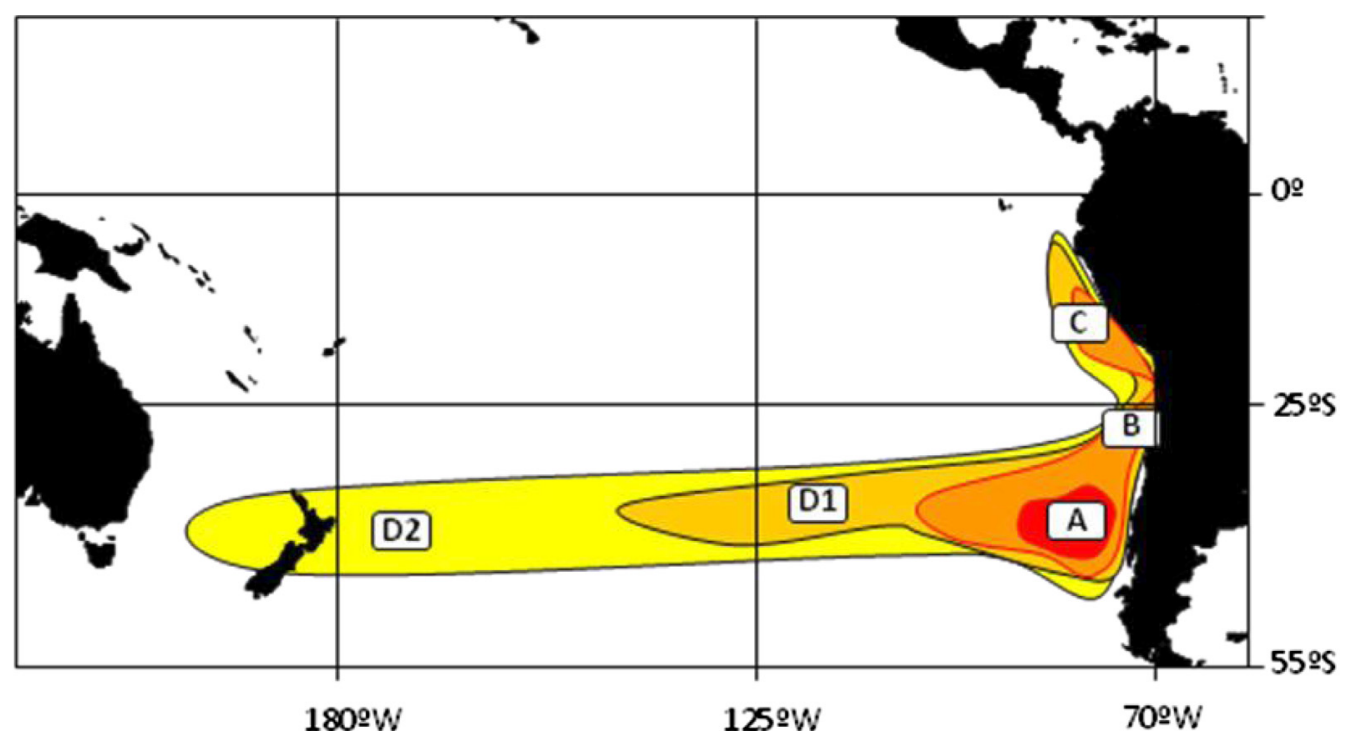

Fig. 1. Extension and abundance of the Chilean jack mackerel, during periods of low (red area) to high abundance (yellow area). The letters in rectangles show the major patches of density. A: Central Pacific-Centre South Chilean stock; B: Northern Chilean stock; C: Peruvian stock; D1 and D2: Central South and Southwest Pacific Ocean stocks respectively.

T. murphyi also presents a wide extension in international unregulated waters, making the species available to any fishery. To date, the main fishing fleets come from Chile, Peru, Russia, China, the European Union, New Zealand and Australia. The demographic strategy and the geographical position of T. murphyi increase the risk of overfishing when the stock decreases. These conditions make a regulation agreement vital. T. murphyi has therefore become a concern for the South $\mathrm{Pa}-$ cific Region Fisheries Management Organization (SPRFMO: www.southpacificrfmo.org). Scientific studies have been undertaken, with one objective being to define the actual population structure of T. murphyi stocks in the South Pacific and recommend sound regulation rules. Indeed, fish stock management would need to be adapted to the population characteristics of this species. If there were just a single population, it would require a single overall management strategy, while separate populations, whether these be independent or linked by exchange of individuals, may require separate (albeit not independent) management policies adapted to each. Defining which structure better describes the T. murphyi population is important for management policies. This is the objective of the present paper.

\section{Definition of population structures}

\subsection{Trachurus murphyi spatial distribution}

A series of studies was made by SPRFMO, but resulting hypotheses about $T$. murphyi stock structure showed no general agreement as they suggested a range of population structures from a single global stock to "up to four separate stocks: a Chilean stock which is a straddling stock with respect to the high seas; a Peruvian stock which is also a straddling stock with the high seas; a central Pacific stock which exists solely in the high seas; and, a southwest Pacific Ocean stock which straddles the high seas and both the New Zealand and Australia EEZs" (Anonymous 2008). A schematic diagram of the major locations of potential populations is given, and area of extension of the "Chilean jack mackerel Belt" in periods of low to high abundance (Fig. 1). Usually authors describing metapopulations refer to a "source", which is a limited population occupying one particular area that remains permanently inhabited during low abundance periods (this would be represented by region A, Fig. 1). The source is supposed to be the only permanent population area, from which all other patches existing during high abundance periods originate.

\subsection{The three major types of population distribution}

Populations can occupy space in different ways. Kritzer and Sale (2004) classified the different structures that populations can take in a given space into three groups, from highly separated subpopulations to a single homogeneous global population (Fig. 2).

The criteria used by these authors were related to observed biological cycles. These cycles can be described by the "migration triangle" (Harden Jones 1968), in which three particular locations can be encountered in a life cycle: (1) area of adult spawning, (2) area of larvae and juveniles, and (3) area of feeding adults.

The three groups defined by Kritzer and Sale (2004) are as follows:

- A "network of closed populations", where each subpopulation in the area has a particular cycle and where no exchange between subpopulations takes place. Populations are completely independent and live separately. This pattern can lead to speciation.

- A "patchy population", where there is a single cycle for the whole population and where the individuals "move frequently among habitat patches and may reproduce in 
A. Network of closed populations.
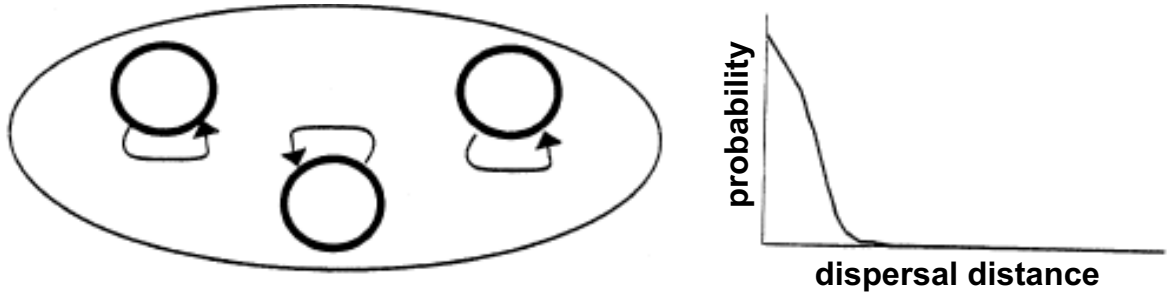

B. Metapopulation.


C. Patchy population.
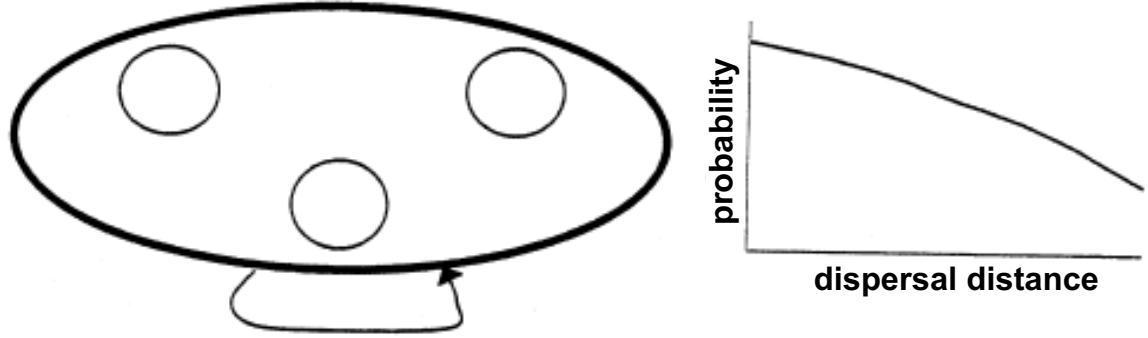

Fig. 2. Three types of spatially-structured populations with generalised dispersal curves for each local population. A: closed local populations with no exchange between them; B: metapopulation; C: patches of high density inside a single "patchy population" (from Kritzer and Sale 2004).

several patches during their lifetime" (Ovaskainen and Hanski 2004). This group requires either a common spawning area for the whole population or the possibility for every individual to spawn in any spawning grounds, and implies that the "patches" are mostly growing/feeding areas.

- A "metapopulation", where the subpopulations have particular cycles but where some exchange between them still occurs: "individuals remain all their life in their natal population, and movements among populations are infrequent, though migration rate is high enough to allow eventual recolonization of habitat patches where a local population has gone extinct" (Ovaskainen and Hanski 2004). Each subpopulation is autonomous but a few individuals maintain links between the different populations (genetic mixing).

Using samples from waters by Centre-South Chile, North Chile, Peru, mid-ocean (at the point $91^{\circ} 20^{\prime} \mathrm{W}, 32^{\circ} 30^{\prime} \mathrm{S}$ ) and New Zealand, genetic studies on mitochondrial DNA and microsatellites identified a single overall genetic population in the Pacific Ocean (Poulin et al. 2004; Cardenas et al. 2009). These results were confirmed by Ashford et al. (2011): by comparing the chemistry of the otolith nucleus between the western and eastern South Pacific Ocean, Chile and Peru. These authors observed a significant heterogeneity among population sampling areas,but no consistent differences, and they concluded that "discrete population hypotheses do not account for the data". Thus, all the fish from New Zealand came mostly from the spawning area off central Chile (after Asford et al. 2011). Things are less clear for the Peruvian area, where, if at least "half of the adults have spent their early life further south", another part of this adult stock would represent "fish that were spawned in a protected area inshore".

Using migration studies and egg and larvae distributions, Arcos et al. (2001) applied Harden Jones' migration triangle to the Chilean area, producing a schematic diagram of T. murphyi migratory behaviour in this part of its distribution area (Fig. 3).

These population analyses, based on genetics, otholit chemistry and egg and larvae surveys, convincingly refute completely independent discrete self-recruiting populations. Thus, the hypothesis of a network of closed populations can quite safely be rejected. The question remains as to whether T. murphyi is organised into a unique patchy population or a metapopulation.

\subsection{The patchy population hypothesis}

The patchy population hypothesis (Ovaskainen and Hanski 2004) considers a single population that expands and contracts according to its abundance, but with a single biological cycle (Fig. 2). When the abundance is large, some parts of the distribution area act as subpopulations, at least for exploiting new 


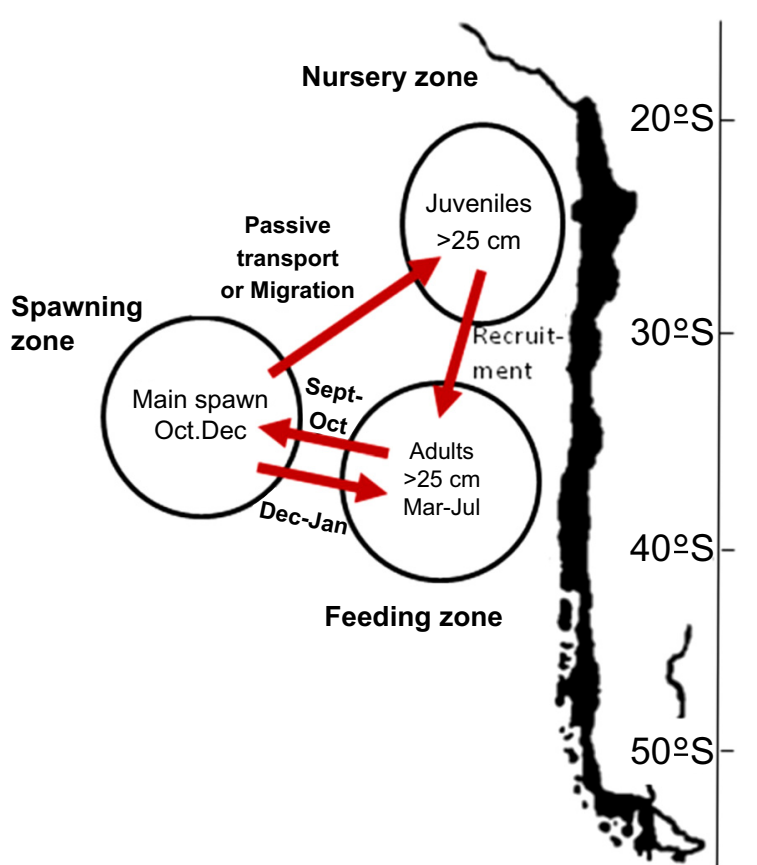

Fig. 3. Schematic diagram of T. murphyi migrations in the CentreSouth area, from catch data and egg-larvae surveys (from Arcos et al. 2001).

feeding areas, i.e., the adults can colonize favourable areas, while the general biological cycle remains unchanged.

This patchy population hypothesis generally implies the existence of a common spawning area for the different subpopulations. According to Ashford et al. (2011), different spawning areas can exist together as long as there is no particular preference on the part of the adults towards one of them. Also, a major characteristic of a patchy population is the absence of a "source population": any part of the population that is reproducing is theoretically able to "regenerate" the whole population after a collapse. The difference in space occupation, i.e., the existence of "feeding subpopulations", is directly linked to the global abundance. There is no possible genetic or biological divergence between the subpopulations. From this hypothesis, we propose a general schema of the hypothesized T. murphyi patchy population in Figure 4A.

\subsection{The metapopulation hypothesis}

The metapopulation hypothesis (Levin 1969) considers that subpopulations can have autonomous (and eventually divergent) lives. We present a diagram of this hypothesis in the case of T. murphyi (Fig. 4B), where independence between the subpopulations is assumed. In this case, the fish inside the subpopulations can diverge genetically, at least during a period. This requires a series of conditions that will be examined in more detail below. Each subpopulation is mostly linked to a particular spawning area, but a small, albeit significant, quantity of adults may move from one spawning area to another. Contrary to the patchy population, the existence of a source population is one key characteristic of a metapopulation. This source requires particular attention in terms of stock assessment and management.

\section{Trachurus murphyi population structure: the biological evidence}

A review of unpublished data was presented by SPRFMO, describing the state of the art for the main biological characteristics of T. murphyi (www.southpacificrfmo.org for a list of reports). Using this set of knowledge, and taking "migration triangles" (Harden Jones 1968) as a methodological basis for extracting useful patterns for differentiating populations from the complete set of key biological patterns, we can describe the four major biological areas for T. murphyi, using a comparative approach between patchy and metapopulation structures:

- The spawning areas. Whether the population has a single spawning area or multiple ones is a strong indication of whether or not there are separate triangles and, therefore, separate subpopulations.

- The larvae-juvenile areas. Areas where fish spend the early life stages are related to environmental conditions.

- The adult feeding and growing areas. "Patches" of high density can be related to larger abundance of prey, or to non-trophic characteristics. Therefore, knowledge of the diet and the plasticity of T. murphyi behaviour is important (see Konchina 1981; Konchina and Pavlov 1996; Bertrand et al. 2004, 2006).

- The general life cycle, including demographic structures, migrations, genetics, parasitism, etc.

\subsection{Characteristics of the spawning areas}

The existence (or absence) of quasi-independent spawning areas is a key characteristic to determinate the existence of a metapopulation or a patchy population. Therefore, it is important to have a clear idea of the spawning areas and cycles, and the demographic structure of the subpopulations. Many studies have been done on these points and we give a synthesis of the results below.

Observations on eggs and larvae in the T. murphyi distribution area, obtained from Russian fishing fleet data, Chilean dedicated surveys and Peruvian surveys (see SPRFMO annual reports for a synthesis), show that eggs are distributed over a large range (Fig. 5). This demonstrates that opportunistic spawning grounds are likely to appear wherever adult fish stocks are present. Evseenko (1987), Serra (1991), Grechina et al. (1994) and Nesterov et al. (2007) argue for the existence of two main spawning areas, respectively in Peruvian and central Chilean waters (Fig. 5). The presence of spawning activity in Peruvian waters was observed every year during the 1980 s and 1990s (Santander and Flores 1983; Gorbunova et al. 1985). Most of these observations were made two to three decades ago but, despite a high variability of fish abundance (extremely low during the period 2000-2010 in Peruvian waters), recent unpublished results confirm that spawning is still observed ( $\mathrm{T}$. Dioses, pers. com., for inshore observations; M. Gutierrez, pers. comm., for offshore observations of a high abundance of larvae west to the Peruvian waters by R/V "Kayo Maru" in 2010). Thus, these spawning areas are not strictly delimited (Sepúlveda et al. 2008). Eggs and larvae can be found almost everywhere, although the main high abundances are observed in two main areas: Peru-North Chile and Centre-South Chile 


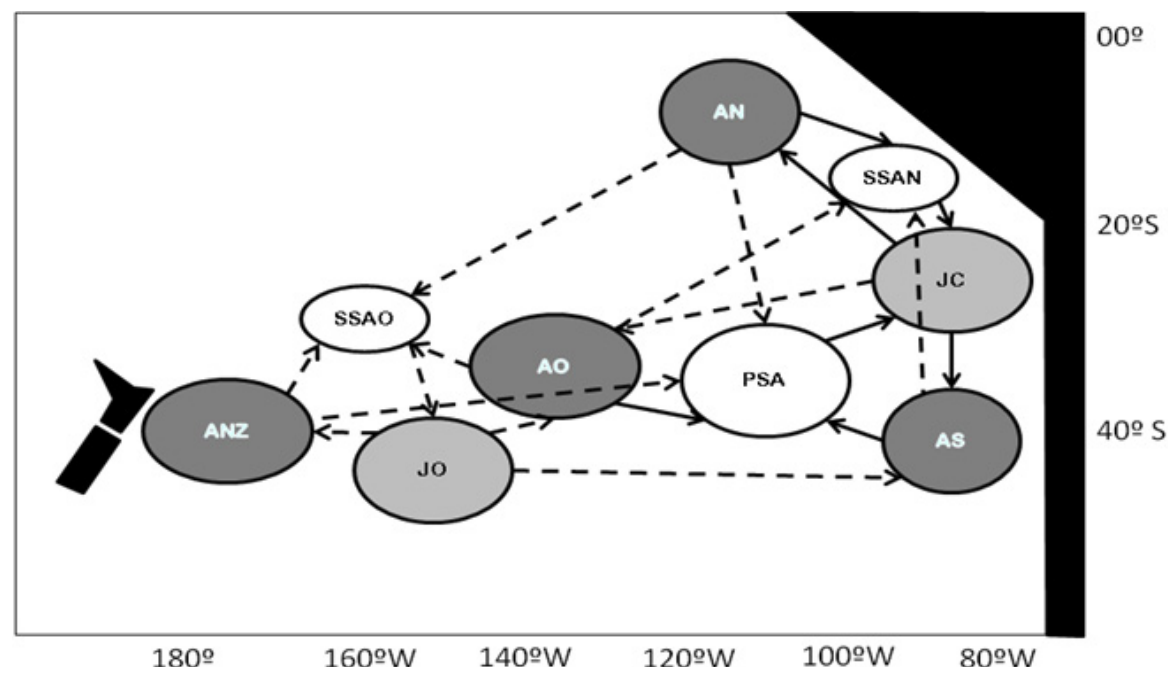

A

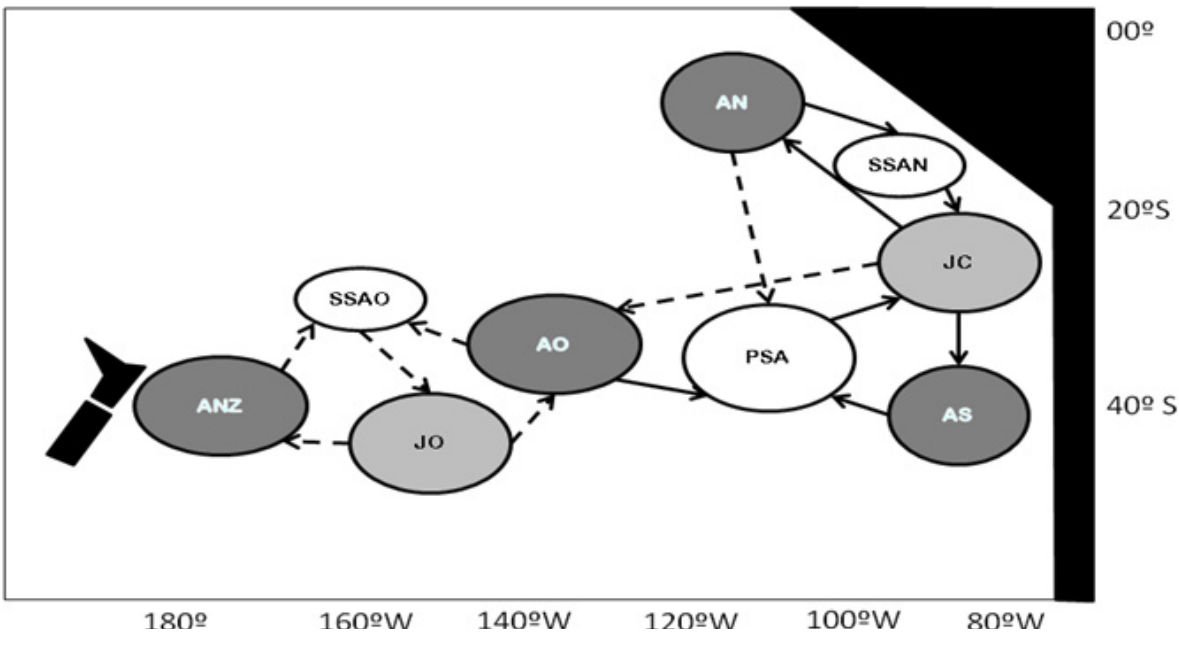

B

Fig. 4. A) Diagram of the patchy population hypothesis applied to T. murphyi. Adult individuals have an equal probability to live and spawn in any one of the feeding and spawning areas. B) Diagram of the metapopulation hypothesis applied to the T. murphyi. Adults come from a single spawning area where they reproduce. Depending on the area of distribution, the metapopulation can be formed of one (low abundance), two (medium abundance) of up to four (high abundance) subpopulations, each one centred on a particular spawning area. Principal spawning area (PSA); secondary spawning area, north (SSAN); Secondary spawning area oceanic (hypothetical) (SSAO); Juveniles, coastline (JC), Juveniles, oceanic (hypothetical) (JO); Adults, south (AS); Adults, north (AN); Adults, oceanic (AO); Adults, New Zealand (ANZ). Solid lines: observed migrations. Dotted lines: hypothetical migrations.

$\left(90-110^{\circ} \mathrm{W}\right)$. It is important to note that at latitudes around $25^{\circ} \mathrm{S}$, the abundance of $T$. murphyi is low along the coastline (see IFOP reports of acoustic surveys, www.ifop.cl): there is a "no jack mackerel zone" in this area, which can be considered as the border between the Peruvian and the Chilean spawning zones as well as between the juvenile (North Chile) and adult (Centre-South Chile) concentrations.

Spawning activity is not strictly driven by abiotic environmental conditions. Cubillos et al. (2008) showed, in the case of the centre-south population, that the sea surface temperature (SST) varied significantly from one year to another in the spawning areas, centred on waters from $15^{\circ} \mathrm{C}(2001)$ to $19^{\circ} \mathrm{C}$
(1999). Actually, the range of distribution of T. murphyi eggs (Fig. 5) covers a variety of environmental conditions in terms of water masses, temperature and other environmental factors (Grechina et al. 1994; Dioses 1995; Barbieri et al. 2004; Sepulveda et al. 1998, 2007, 2009; Cubillos et al. 2008), although always within subtropical waters.

The major spawning area off Chile has been surveyed each year since 1997, using hired fishing ships (the "Rastrillo" surveys: Barbieri et al. 1999, 2001, 2004; Sepúlveda et al. 2007, 2009). Results show a rather good stability in geographic position, but a wide variability in egg density, confirming previous results from Cubillos et al. (2008). 


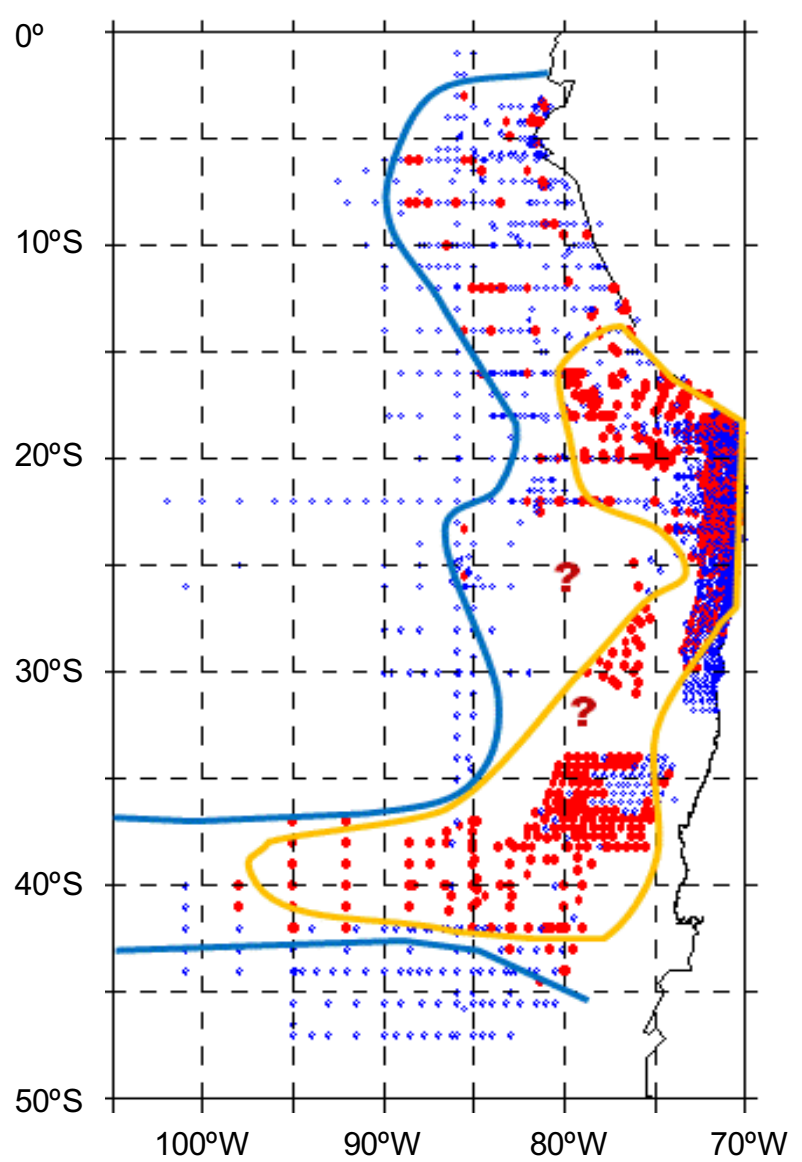

Fig. 5. General distribution of T. murphyi eggs in the SE Pacific, synthesized from historical and recent data by Sepúlveda et al. (1998). Blue dots: sampling stations with no eggs detected; red dots: sampling stations where eggs were observed. Orange line: our vision of the limits of the major spawning areas (redrawn from Grechina et al. 1994). Blue line: the extreme limits where eggs were found. Note the lack of data from $25^{\circ} \mathrm{S}$ to $35^{\circ} \mathrm{S}$ in the Russian database, this area belonging to the Chilean EEZ (represented by the question marks).

Results on spawning have led to the following major conclusions: (i) $T$ murphyi has no major specific requirement in terms of temperature (SST) for its spawning areas, as long as these are in subtropical waters; (ii) a principal and permanent spawning area occurs in the Chilean EEZ and adjacent international waters between latitudes $30^{\circ} \mathrm{S}$ and $42^{\circ} \mathrm{S}$; (iii) during high abundance periods, besides the principal spawning area west of $75^{\circ} \mathrm{W}$ between latitudes $35-40^{\circ} \mathrm{S}$, coastal spawning areas are observed between $12^{\circ} \mathrm{S}$ and $40^{\circ} \mathrm{S}$, with a major concentration along the coastline between $15^{\circ} \mathrm{S}$ and $25^{\circ} \mathrm{S}$, and sporadic spawning over the whole distribution area (from $4^{\circ} \mathrm{S}$ to $45^{\circ} \mathrm{S}$ ); (iv) during lower abundance periods, only the major spawning area off Centre-South Chile remains, together with a more reduced spawning area in South Peru-North Chile; (v) T. murphyi tends to scatter in the spawning areas (Barbieri et al. 2004). We can conclude that the Chilean jack mackerel spawning strategy is adaptive and not strictly dependent on homing: the fish will spawn in the first convenient area encountered, and will then keep this new spawning area as long as it remains "favourable". We still do not know precisely what a "favourable" spawning area is for the Chilean jack mackerel, and research should be undertaken in this field.

\subsection{Demographic structure of T. murphyi stocks in Chile and Peru}

- The appearance of specific demographic strategies implying different recruitments in the different subpopulation areas is good evidence for the existence of a metapopulation. Information on the demographic structure in age was calculated by SPRFMO (2011) from the catches in three regions (Fig. 6): North Chile (NC, lat. $18-23^{\circ} \mathrm{S}$ ), named "fleet 1"; Centre-South Chile (CSC, 30-45 ${ }^{\circ}$, 79-90 $\left.{ }^{\circ} \mathrm{W}\right)$ or fleet 2, for the period 1975-2011; far north (FN, mostly Peru and marginally Ecuador, north of $18.5^{\circ} \mathrm{S}$ ) or fleet 3, for the period 1980-2011. The offshore Russian (formerly Soviet) fishery, or fleet 4 , is difficult to compare with the other three because it suffered a long interruption (from 1992 to 2002) and its fishing gears are different (pelagic trawls instead of purse seines) (see Fig. 6) but it will not be considered any further in this study. Data presented are calculated in proportion of age classes (Fig. 6), which means some smoothing has been applied. In order to let the reader conclude from the raw data, we present the raw histograms per year class for CSC, NC and FN in Annex 1 . We found also interesting to display the catches per year (1975-2011) and per fleet (Fig. 6, below), in order to compare the age structure per fleet and the catches per fleet.

From these histograms (Fig. 6 and Annex 1), we can extract the following observations:

- When comparing the different fishing areas, one can split the period into 4 sub-periods: (i) before 1986, when no clear evolution is visible in the demographic structures in the four fisheries; (ii) the period 1986-1993, when a clear evolution of classes recruited in 1985 and 1986 is observed and these year classes are visible in the four regions and represent the bulk of the catches over the whole subperiod; (iii) the period 1994-2003, when a difference is visible between North Chile (NC) and Centre-South Chile (CSC) as juveniles are only present in NC, young adults disappear from $\mathrm{NC}$ at age 4 and appear at this same age in CSC, but no such separation can be seen in the far north (Peruvian) fishery (FN); and (iv) during the period after 2003, clear cohort dynamics appear in the Peruvian zone but are less clear in the Chilean fisheries. It should be noted that this period (until 2009) was a period with very low abundance and catches of T. murphyi off Peru. Almost no catchable aggregation of jack mackerel was observed offshore during acoustic surveys and fishing operations. Only few very coastal jack mackerel were observed.

- The CSC fishery exploits the widest distribution of year classes, with the most regular evolution. Apart from two occasions (1989 and 1998-1999), juveniles were not significantly present in the catches in this area. This reinforces the idea that CSC represents the "source population" where most adults occur and spawn. 


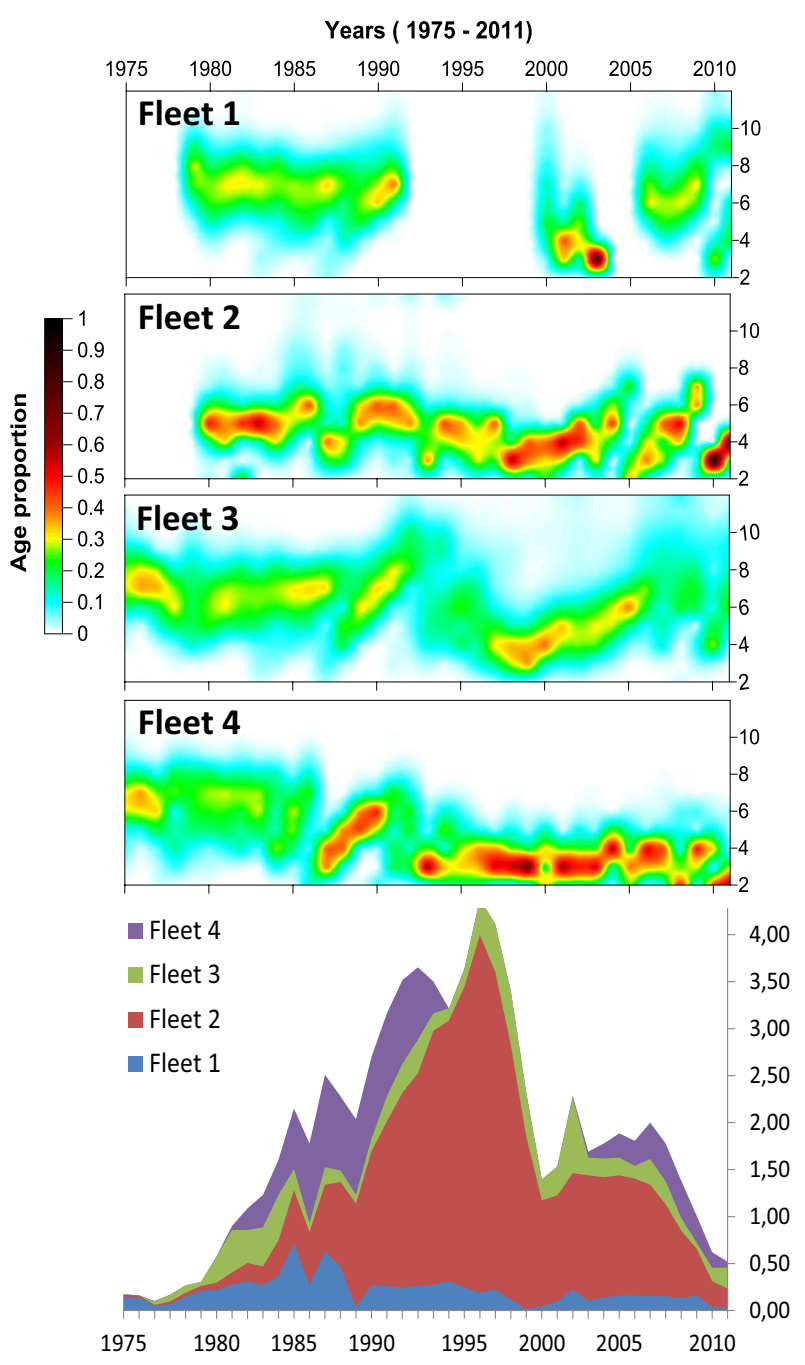

Fig. 6. Description of catches for T. murphyi during the period 1975 (beginning of the fishery)-2011. Above: detail of proportions of cohort in the yearly catches for year classes 2 to 10 . The 4 main fleets are the North Chile (fleet 1), Centre-South Chile (fleet 2), Peru (fleet 3) and USSR-Russia (Fleet 4). Below: evolution of catches for the same 4 fleets (in million tonnes). Five main periods are visible in the catches: 1975-1985, increasing of the catches due to the development of the fisheries; 1985-1995, period of very high abundance and catches by all the fisheries (the end of the USSR catches was due to political decisions, until the Russian fleet came back in 2002); 1996-2000, strong decrease of the fisheries: 2001-2008, relative stability of the catches; since 2008, new decrease and quasi collapse of the stocks. From SPRFMO (2011, www.southernpacificrfom.org).

- The NC fishery has clearly been the area of concentration for juveniles in the Chilean fisheries $(\mathrm{NC}+\mathrm{CSC})$ since 1994. From this observation, we can hypothesize that the adult zone for the CSC group moved southward in the early 1990s. After 1994, CSC and FN became completely distinct areas of adults, separated by the NC juvenile area. Two successive high recruitments appeared recently in the NC fishery: one in 2008 and another in 2009.

- The FN area, mostly represented by the Peruvian fishery, presents distinct characteristics. The juveniles were observed during the whole period but always mixed with adults (although in recent years, juveniles were encountered further north than the adults). From this point of view the difference between $\mathrm{NC}$ and $\mathrm{FN}$ has been especially marked since 2005: fish of age 7 were observed in 2005 in FN, while jack mackerels of this age have not been observed in the NC catches since 1992. The year 2005 is also interesting because a large new cohort appeared in $\mathrm{FN}$ and represented the most important exploited stock from 2005 to 2009 , although it was not significantly different from former cohorts in NC. However, it rapidly disappeared in NC, probably by moving to the CSC where it did not represent a strong class either. Recruitment in 2005 was much greater in FN than in NC-CSC. Finally, a very strong cohort born in 2007 appeared in 2009 and was heavily exploited in 2011, providing almost half of the total catch of T. murphyi in that year. This fact is unexpected because the strongest spawning observed during routine surveys performed by observers in the central south fisheries actually occurred in 2008. Catches in Peru during January-June 2011 reached 240000 tons of fish 28$32 \mathrm{~cm}$ long. The same year class (born in 2007) was also recorded in the Centre-South Chile and Central Oceanic areas, but in smaller quantities, and catch statistics provided to SPRFMO by the fishing fleets showed that it remained almost insignificant (www.southpacificrfmo.org). This cohort distribution in $\mathrm{FN}$ is different from that observed in $\mathrm{NC}$, where the most recent important cohort was born in 2008 and appeared in the fishery in 2010.

It is worthwhile noting that ENSO (El Niño Southern Oscillation) events are almost always followed by a strong recruitment, as a number of authors have stated (Muck and Sanchez 1987; Dioses 1995; Ganoza 1998; see a general comment by Bertrand et al. 2004). In the histograms of Annex 1, we show the cohorts born during ENSO events in white colour, i.e., those with an ENSO event 2 years before their recruitment. These data show that even though no strong biomass was observed in some periods after El Niño, these cohorts almost always dominated the population structures. Most of the ENSO cohorts can be observed for longer on average than the others. This could be linked to an observation made on school-type proportions in Chilean waters during the period 1991-1999, when the dense structures (big schools and dense layers) decreased in proportion during the ENSO events (Gerlotto and Barbieri 2000). T. murphyi disperses during spawning, the coincidence of these high recruitments 2 years after ENSO events and the fact that fish tend to scatter during ENSO events are a good confirmation that high recruitments of $T$. murphyi could be at least partly linked to ENSO events.

\section{Discussion}

\subsection{Population concepts}

The patchy population concept has one simple strong requirement, that each individual is equivalent to any other. There are no identified groups or sub-populations (and consequently no "source" population) among the patches that have particular dynamics. This requirement has consequences 
for spawning: either there is a single common spawning area where all the adults spawn, or, if there are different spawning areas, individuals are not linked to a particular one and can spawn in any of them, resulting in (1) an absence of genetic divergence in the whole distribution area, and (2) a homogeneity in demographic structures in all patches. The description of the T. murphyi distribution as a "patchy population" does not seem fully convincing because the long distances between some adult feeding areas and the spawning areas are in contradiction with the definition. It is unlikely that $T$. murphyi could indifferently spawn in any place inside the whole spawning area. The differences in demographic structures between the patches also go against the patchy population hypothesis. T. murphyi thus does not present the characteristics of the patchy population, except maybe as a transitional stage during periods of extension of the stock.

A metapopulation, in contrast, presents a series of specificities and characteristics that have been widely discussed in the literature, and we need to go into greater detail in order to know whether this concept fits the characteristics of T. murphyi.

The metapopulation was first defined by Levin (1969) as: "a population of local populations which were established by colonists, survive for a while, send out migrants, and eventually disappear. The persistence of a species in a region depends on the rate of colonisation successfully balancing the local extinction rate". The concept has been proved heuristic and was substantially enriched in recent decades. McQuinn (1997) presented a noteworthy synthesis of these ideas when applying them to the populations of Atlantic herring, and synthesized Levin's ideas as four characteristics: “(i) There is a large number of sites, each supporting a single local population; (ii) Each local population has a probability of going extinct that may depend on its genetic composition; (iii) The allele frequencies are governed by the classical genetic equations; and (iv) Vacant sites are recolonized by migrants from within the metapopulation" (McQuinn 1997).

Grimm et al. (2003) indicated that there is also asynchrony in local population dynamics because of partial closure of local populations that counteracts homogenization of regional dynamics.

The definitions and description of the metapopulation concept show that the conditions for a metapopulation to exist are more restrictive than those for a patchy population. It is therefore important to list these conditions, and then to evaluate whether T. murphyi fulfils these requirements or not (Table 1). To make this list, we used the twelve conditions proposed by Hanski (1999), to which we added four more conditions (Table 1).

\subsection{Selection of the most adapted population structure}

Considering the metapopulation hypothesis, T. murphyi fulfils most of the essential requirements (Table 1). Nevertheless, there are few critical conditions that apparently do not fit with the metapopulation definition. Two of them, conditions 3 and 16, are actually in some way contradictory with Levin's definition. Indeed, the different populations cannot be considered as discrete and it is impossible to draw clear borders between them with the existing data (condition 16): T. murphyi has a high plasticity (Bertrand et al. 2004, 2006), and can be encountered in the whole "Pacific belt". Condition 3 should also be discussed because we observed contradictory results: on the one hand, local differences occurred in the demographic structures but, on the other hand, there is not complete independence between the major dynamics of the different populations, as synchrony of variations in abundance, migrations, etc. is frequently observed. This was obvious in the late 1990s to early 2000s when all the subpopulations decreased synchronously, from Peru and Chile to New Zealand. In the South Pacific Ocean, the strong climatic signals at interannual (e.g., El Niño southern oscillation: Barber and Chavez 1983), decadal (Chavez et al. 2003) and centennial (Sifeddine et al. 2008; Gutiérrez et al. 2009) scales are known to have a strong impact on the whole ecosystem, ergo on fish stocks. In this highly dynamic context (see Chavez et al. 2008), T. murphyi has developed a strategy of a few successful recruitments (in average 1 every 5 years) that lead the whole population and consequently its exploitation (Konchina and Pavlov 1999). However, we cannot determine whether all the recruitments depend on one or several of these signals.

We believe that the requirements for metapopulation structure (Table 1) that are not fulfilled by T. murphyi are not applicable to pelagic populations, especially jack mackerel, because of their dimensions and spatiotemporal variability. Pelagic populations with large ranges of distribution present particular characteristics that make it difficult to apply some items from the list of conditions for a patchy vs. metapopulation structure to exist as established in the literature. Table 1 presents a series of conditions that have been defined mostly for small populations of rather sedentary species, and in the future, we should draw a particular series of definitions that fit with pelagic fish with large distribution ranges. This remark has already been made by Hanski (1999): "perhaps most striking is the virtual lack of unambiguous evidence for the threshold condition for metapopulation persistence". Considering this point, the discussion on whether the organisation is that of a metapopulation or another structure must be led by empirical observation and practical needs: "The metapopulation concept is more of an analytical approach to be used when appropriate rather than a set of strict criteria and definitions (Hanski 1999)" (cited by Kritzer and Sale 2004).

The Chilean jack mackerel appears more likely to be organised into a metapopulation than a patchy population and we will focus on this structure for evaluating the consequences in terms of management. The population located off central Chile is the most important in terms of abundance. It also produces "demographic pulsations" linked, among other factors, to ENSO signals, which induce periodic high recruitments invading the jack mackerel belt. This population is certainly the source population and this fact will require specific modelling (Kritzer and Sales 2006) and recommendations for management policy.

\subsection{A metapopulation model for the Chilean jack mackerel}

Under a metapopulation hypothesis, a specific cycle appears in the north that is different from that in the south. In the 
Table 1. Conditions for a metapopulation to exist (extended from Hanski 1999) applied to the case of the Chilean jack mackerel.

\begin{tabular}{ll}
\hline & Population characteristics \\
\hline 1 & $\begin{array}{l}\text { Population size or density is significantly } \\
\text { affected by migrations }\end{array}$ \\
2 & $\begin{array}{l}\text { Population density is affected by patch } \\
\text { areas and isolation }\end{array}$ \\
3 & Existence of asynchronous local dynamics \\
4 & $\begin{array}{l}\text { Population turnover, local extinctions and } \\
\text { establishment of new populations }\end{array}$
\end{tabular}

The case of the Chilean jack mackerel (CJM)

Yes, obviously: large movements between subpopulations related to environmental changes

Yes: CJM obviously presents a patchy distribution since its density is not constant throughout its distribution range. Small groups of old adults are still observed by the artisanal fishery along the shore

Apparently no, but these characteristics are possibly within (hidden by) a global synchrony due to strong basin-scale environmental signals

Probably, the case of New Zealand where CJM was unknown before the 1970s, is a good example. Also paleoecological results show a series of rise and fall in Peru during the last centuries and a strong increase during the 1970s (Gutiérrez et al. 2009)

$5 \quad$ Presence of empty habitats

$6 \quad$ Metapopulations persist despite population turnover

Yes if we consider again the case of New Zealand and Tasmania

Probably: fisheries have always showed the presence of fish in the central, Chilean and Peruvian areas. There is also sporadic presence of small groups of very large sedentary adults along the South America coastline

Yes, probably

? This condition probably does not fit with the case of a large pelagic population isolation

$9 \quad$ Patch occupancy depends on patch area and isolation

10 Spatially realistic metapopulation models can be used to make prediction about metapopulation dynamics in particular fragmented landscape

? This condition probably does not fit with the case of a large pelagic population

? No modelling exercise done so far has tested the metapopulation hypothesis. Models have been constructed on the basis of the patchy population hypothesis (e.g., SPRFMO 2010)

11 Metapopulation coexistence of competitors

12 Metapopulation coexistence of prey and its predator

Yes: presence of mackerel overlapping with CJM at least in the Peruvian waters

? This condition probably does not fit with the case of a large pelagic population

Yes (Cardenas et al. 2005, 2009)

No: although genetics suggests that there is a single biological group, Ashford et al. (2011) found some local differences

15 Existence of source/sink populations

Yes: the central offshore population is clearly the source, Peruvian and western Pacific being "sink" populations

Clearly no 


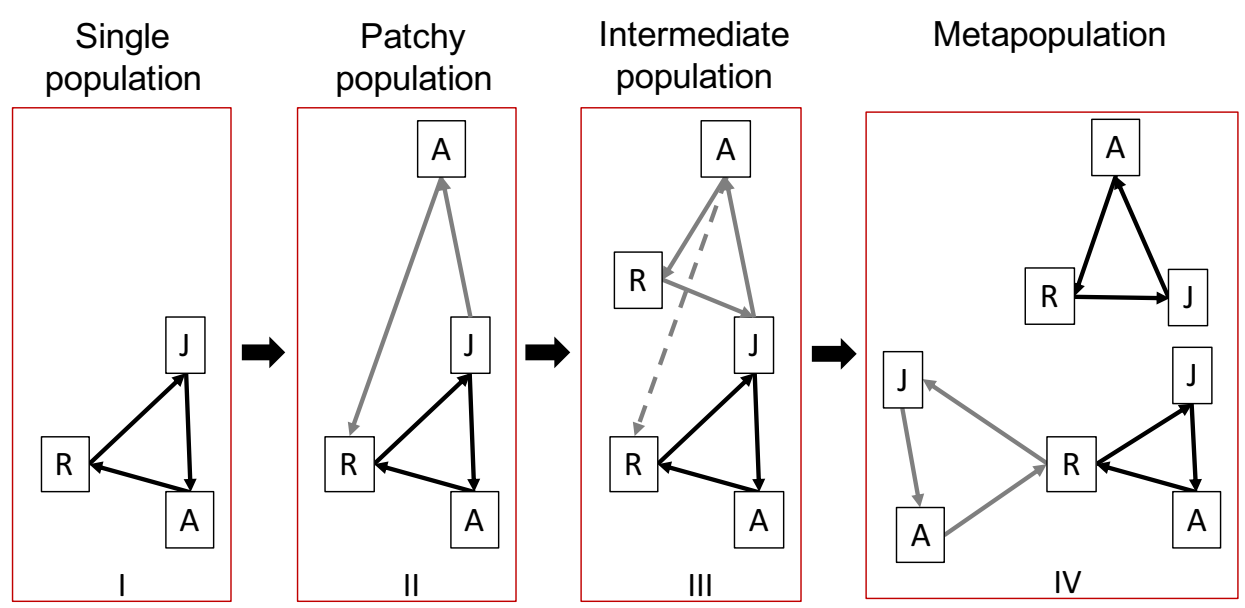

Fig. 7. Description of the different stages of organization depending on overall abundance. I) Single population: this structure represents a small population without any relationships with others; this case also represents the source population in period of stock collapse. II) Patchy population: this structure appears when new feeding grounds are colonized by fish during periods of increasing abundance; the spawning area is common to all adults. III) Intermediate: this is a hypothetical intermediate stage between patchy and metapopulation, when patches of adults encounter favourable conditions to spawn outside the source spawning zone: some of the adults continue to go to this new zone. IV) Metapopulation: requires a period of high abundance to be created, then can remain even after the overall biomass has dropped off, as long as conditions for survival of the subpopulation exist. Letters indicate the location of adults (A), juveniles (J), and spawning adults (R). Arrows indicate the migration of fish from one area to the other during their life cycle. Arrows in dotted lines show a provisional migration route.

north, young adults, instead of going to the common spawning area, create a new one specifically for their population. A specific spawning area for each subpopulation is essential in the definition of a metapopulation, as it is the only way for them to be able to diverge genetically from the parent population. This creation is made easy considering that $T$. murphyi is rather opportunistic and tends to spawn as soon as conditions are favourable: we have seen that no real homing exists as far as spawning is concerned and local spawning areas can appear and remain at any place compatible with the main environmental requirements for spawning. In such cases, the cycle becomes autonomous and a metapopulation can appear. This metapopulation model is in agreement with the general hypotheses from Petitgas et al. (2010) who observed the existence of different emerging behaviours in a population that produces migrant and non-migrant groups. The fact that the fish may share a common juvenile growth area is also observed in the demographic structures of the stocks in Peru and Chile, where the distribution of year classes are symmetric in latitude. Nevertheless, exchanges still can occur between individuals from the two sub-populations, as stated by McQuinn (1997) for the herring, and Petitgas et al. (2010) for the anchovy in the Bay of Biscay.

We propose a schematic model (Fig. 7) describing the possible way in which population structures evolve according to the overall abundance of fish, using Harden Jones' triangles as a model. We defined 4 stages:

I. Single population. This structure represents a small population without any relationships with others. It may be the case with $T$. murphyi and represents the source population in periods of stock collapse.

II. Patchy population. This structure appears when new feeding grounds are colonized by fish during periods of increasing abundance (e.g., high recruitment periods).
III. Intermediate structure. This is a hypothetical intermediate stage between a patchy population and a metapopulation, when patches of adults encounter favourable conditions to spawn outside the source spawning zone but a consistent proportion of adults still go back to the original spawning zone.

IV. Metapopulation. Requires a period of high abundance to be created by colonization of feeding and spawning areas, then metapopulations can remain even when the overall biomass drops off, as long as conditions for surviving of the subpopulation exist: the return to the single population stage is not necessarily linked to decreases in abundance, and the metapopulation structure would remain even during low global abundance periods, until a given threshold was reached. During such a period the different subpopulations would have specific histories. Inversely, some particular sub-populations could also vanish, even in periods of high abundance, if biotic or abiotic conditions in their own area become unfavourable.

Considering the huge variability of $T$. murphyi abundance (Fig. 7B), it is likely that this pattern has existed several times in the existence of this species. Indeed, when observing the total catches for jack mackerel during the period 1970 (beginning of the fishery) to 2011, five main periods are visible (Fig. 6): 1970-1985, a period of increasing of the catches due to the development of the fisheries during a period of increasing population; 1985-1995, a period of very high abundance and catches by all fisheries (the USSR catches halted for political reasons, until the Russian fleet returned in 2002); 1996-2000, a strong decrease of the global abundance and catches; 2001-2008, relative stability of the catches; 2008-2010, a new decrease and near stock collapse. A change in this last pattern of dynamics has been observed since 2011, with T. murphyi particularly abundant in the FN 
fishery. It is too soon to draw new conclusions but the next few years will be especially interesting to study.

Considering our model, particular attention should be given to the overall biomass and the local abundances in order to define which one of the situations described is present and what management rules should be selected. This means that the recruitment in the whole potential distribution area must be surveyed seasonally.

\section{Conclusion}

The question asked in this paper was: which one of the two models, metapopulation or patchy population, better represents the current situation. We have seen that there are different cohort histories, some being common to the two areas: $(\mathrm{NC}+\mathrm{CSC})$ and FN, while some others remain located mostly in one area. In the case of spawning areas, the results tend to favour the metapopulation hypothesis. Nevertheless, the frequent resetting (Bakun and Broad 2003) of the ecosystem (e.g., by ENSO and decadal cycles) is unlikely to give enough time for subpopulations to stabilize and diverge genetically.

The need to define as precisely as possible how T. murphyi is organized is particularly important for management purposes. In the present context of overfishing and low population status, if we keep in mind that a significant part of the total adult population is located in unregulated international waters, then the whole population is in danger. As long as the global abundance was high enough to fill-up the Chilean EEZ, and the other populations (mostly Peruvian and oceanic) were healthy, the bulk of the catch was taken from them while the "source" was protected by the highest cost of going offshore for fishing. This is no longer the case. As pointed out by several authors (e.g., Hanski 1999), a practical and heuristic definition is needed before any management decision be taken. From a metapopulation perspective, the central offshore stock represents the source and therefore is particularly important. Specific management of this part of the metapopulation becomes a priority, and in case of collapse of the other sub-populations it could be recommended to close or strictly restrict the fishing activity in this particular area. The "source area" can be geographically defined as the rectangle surrounding the major spawning area, i.e., from $30^{\circ} \mathrm{S}$ to $40^{\circ} \mathrm{S}$ and from $82^{\circ} \mathrm{W}$ to $98^{\circ} \mathrm{W}$. An important research effort should be devoted to this area, especially as far as eggs and larvae are concerned, as it appeared that the T. murphyi population strategy is led by the occurrence of strong recruitments. During low recruitment periods, the fishery should be strongly limited. In any case, the source population should be carefully monitored with precautionary regulations, since the whole population depends on the health of the source population. The other areas (Peruvian area, coastal Centre-South Chile and the oceanic area west of $98^{\circ} \mathrm{W}$ ) should be considered as supporting separated subpopulations that have a weak impact on the source. When the global population is high and these subpopulations are important (e.g., during the 1980-1990s or since 2010), specific regulations should be designed for each one of them, that are different from the regulation inside the source area. However, managers of all regions must work together and build specific regulations according to the joint analysis of the international scientific community, using the best available information (including access to data collected by fishing vessels).

Considering the population as being organised into a metapopulation structure is both a "precautionary" approach (the source is considered as the most important part of the global population and its safety is essential) and an optimal approach (allowing an optimised management of each one of the different parts of the population); therefore, it permits the best exploitation scheme. This leads us to recommend, as a precautionary approach, the hypothesis that $T$. murphyi is organized in a metapopulation. We should also point out the importance of pre-recruitment surveys: we have seen that the recruitment is a key factor in jack mackerel dynamics and that its magnitude is still unpredictable. This is feasible through the use of fishers' observation data.

Another conclusion that can be drawn is that the concept of metapopulation has been designed on cases from terrestrial and rather small sedentary populations of animals. It is not surprising that the definition and some of the conditions defined do not apply to a worldwide highly versatile and migrating pelagic fish population. Application of the concept to such animals has always been difficult and, although in some cases, it has given remarkable results (e.g., on herring, probably due to the homing behaviour of herring as benthic spawners, see McQuinn 1997), in several others no clear conclusion could be obtained. This was the case for the European horse mackerel Trachurus trachurus, which also presents a wide distribution area (from Norway to Mauritania and Greece) but the genetic analysis did not show, as in the case of T. murphyi, any difference in the different geographically separated populations (EU Project HOMSIR: www.homsir.com).

In order to go further in the analysis of this metapopulation application to large pelagic stocks, there is a need for some theoretical work to evaluate how these populations can be analysed inside the framework of the metapopulation concept, and probably to write adapted definitions for these species.

Acknowledgements. The authors are particularly grateful to $\mathrm{Dr}$ Aquiles Sepúlveda, for his help in the beginning of this work and with whom a preliminary analysis of population structures of jack mackerel was produced for the South Pacific Region Fisheries Management Organization, SPRFMO (see SPRFMO working documents, 2009), making the present work possible. Our thanks go also to Dr A. Grechina who made his bibliographical synthesis available and to $\mathrm{Dr}$ J. Ianelli for providing the T. murphyi catch-per-age data for the demographic analysis. This work is a contribution of the LMI DISCOH.

\section{References}

Anonymous, 2008, Chilean jack mackerel workshop. Report of the South Pacific Regional Fisheries Management Organization Chilean jack mackerel workshop 30 June-4 July 2008, Santiago, Chile.

Arcos D., Cubillos, L., Nuñez S., 2001, The jack mackerel fishery and El Niño 1997-1998 effects off Chile. Prog. Oceanogr. 49, 597-617.

Ashford J., Serra R., Saavedra J.C., Letelier J., 2011, Otolith chemistry indicates large-scale connectivity in Chilean jack mackerel (Trachurus murphyi), a highly mobile species in the Southern Pacific Ocean. Fish. Res. 107, 291-299. 
Bakun A., Broad K., 2003, Environmental 'loopholes' and fish population dynamics: comparative pattern recognition with focus on El Nino effects in the Pacific. Fish. Oceanogr. 12, 458-473.

Barber R.T., Chavez F.P., 1983, Biological consequences of El Niño. Science 222, 1203-1210.

Barbieri M.A., Cordova J., Lillo S., Peña H., Grechina A., Nuñez S., Sepulvbeda A., Miranda L., Rebolledo H., 1999, Análisis de la estructura del stock de jurel fuera de las aguas juridiccionales. Inf. Téc. FIP-IT/97-05b (www.fip.cl).

Barbieri M.A., Cordoba J., Espejo M., 2001, Ecoprospecciones de jurel (Trachurus murphyi) en la zona central de Chile (Operaciones Rastrillo). Metodologías de evaluacion hidroacustica de recursos pesqueros. Comisión Permanente del Pacífico Sur (CPPS), pp. 51-53.

Barbieri M.A., Cordova J., Gerlotto F., Espejo M., 2004, Spatial spawning strategy of jack mackerel (Trachurus symmetricus murphyi) off the central-south region of Chile. Comm. GLOBEC/SPACC Workshop on characterizing and comparing the spawning habitats of small pelagic fishes, Concepcion, Chile, 12-13 January, 2004.

Bertrand A., Barbieri M.A., Cordova J., Hernandez C., Gomez F., Leiva F., 2004, Diel vertical behaviour, predator prey relationships, and occupation of space by jack mackerel (Trachurus murphyi) off Chile. ICES J. Mar. Sci. 61, 1105-1112.

Bertrand A., Barbieri M.A., Gerlotto F., Leivam F, Córdova J., 2006, Determinism and plasticity of fish schooling behaviour as exemplified by the South Pacific jack mackerel Trachurus murphyi. Mar. Ecol. Prog. Ser. 311, 145-156.

Bertrand A., Chaigneau A., Peraltilla S., Ledesma J., Graco M., Monetti F., Chavez F.P, 2011, Oxygen, a fundamental property regulating pelagic ecosystem structure in the coastal southeastern tropical Pacific. PLoS ONE, 6(12): e29558.

Cárdenas L., Hernández C.E., Poulin E., Magoulas A., Kornfield I., Ojeda F.P., 2005, Origin, diversification, and historical biogeography of the genus Trachurus (Perciformes: Carangidae). Mol. Phylogenet. Evol. 35, 496-507.

Cárdenas L., Silva A.X., Magoulas A., Cabezas J., Poulin E., Ojeda F.P., 2009, Genetic population structure in the Chilean jack mackerel, Trachurus murphyi (Nichols) across the South-Eastern Pacific Ocean. Fish. Res. 100, 109-115.

Chavez F.P., Ryan J., Lluch-Cota S.E., Ñiquen M., 2003, From anchovies to sardines and back: multidecadal change in the Pacific Ocean. Science 299, 217-221.

Chavez F., Bertrand A., Guevara R., Soler P., Csirke J., 2008, The northern Humboldt Current System: brief history, present status and a view towards the future. Prog. Oceanogr. 79, 95-105.

Cubillos L.A, Paramo J., Ruiz P., Núñez S., Sepúlveda A., 2008, The spatial structure of the oceanic spawning of jack mackerel (Trachurus murphyi) off central Chile (1998-2001). Fish. Res. 90, 261-270.

Dioses T., 1995, Análisis de la distribución y abundancia de los recursos jurel y caballa frente a la costa Peruana. Informe Progresivo del Instituto del Mar del Perú No. 3 (in Spanish, with an English abstract).

Evseenko, S.A., 1987, Reproduction of Peruvian jack mackerel, Trachurus symmetricus murphyi, in the southern Pacific. J. Ichthyol. 27, 151-160.

Ganoza, F., 1998, Abundancia y comportamiento del jurel (Trachurus picturatus murphyi) a través de prospecciones acústicas de 1983 a 1994. Informe del Instituto del Mar del Perú No. 136, 23-47 (In Spanish, with an English abstract).

Gerlotto F., Barbieri M.A., 2000, Pression de pêche et dynamique du comportement spatial du chinchard (Trachurus symmetricus murphyi). Exposé scientifique du projet ECOS n ${ }^{\circ}$ C97B06.
Gorbunova N.N., Evseenko S.A., Garetovskiy S.V., 1985, distribution of ichthyoplankton in the frontal zones of the Peruvian waters. J. Ichthyol. 25, 67-79.

Grechina A., 1998, Historia de investigaciones y aspectos básicos d e la ecología del jurel Trachurus symmetricus murphyi (Nichols) en alta mar del Pacífico Sur. In: Arcos D. (ed.) Biología y ecología del jurel en aguas Chilenas. Instituto de Investigación Pesquera, Concepción, pp. 11-34.

Grechina A.S., Nuñez S.P., Arcos D.F., 1994, Desove del recurso jurel (Trachurus symmetricus murphyi) en el océano Pacífico Sur. Doc. Técn. Investig. Pesq. (IIP), Talcahuano 3, 1-44.

Grimm V., Reise K., Strasser M., 2003, Marine metapopulations: a useful concept? Helgol. Mar. Res. 56, 222-228.

Gutiérrez D., Sifeddine A., Field D.B., Ortlieb L., Vargas G., Chávez F., Velazco F., Ferreira V., Tapia P., Salvatteci R., Boucher H., Morales M.C., Valdés J., Reyss J.L., Campusano A., Boussafir M., Mandeng-Yogo M., García M., Baumgartner T., 2009, Rapid reorganization in ocean biogeochemistry off Peru towards the end of the Little Ice Age. Biogeosciences 6, 835-848.

Hanski I.A., 1999, Metapopulation ecology. Oxford University Press. Harden-Jones F., 1968, Fish migration. Edward Arnold Ltd, London.

Konchina Y.V., Pavlov Y.P., 1999, On the strength of generations of the Pacific jack mackerel Trachurus symmetricus murphyi. J. Ichthyol. 39, 748-754.

Konchina YV.,1981, The Peruvian jack mackerel, Trachurus symmetricus murphyi, a facultative predator in the coastal upwelling ecosystem. J. Ichthyol. 21, 46-59.

Kritzer J.P., Sales P.F., 2006, The metapopulation ecology of marine coral fishes. In: Kritzer J.P., Sales P.F. (eds) Marine metapopulations. Academic Press, Amsterdam.

Kritzer J.P., Sales P.F, 2004, Metapopulation ecology in the sea: from Levin's model to marine ecology and fisheries science. Fish Fish. 5, 131-140.

Levin R., 1969, Some demographic and genetic consequences of environmental heterogeneity for biological control. Bull. Entomol. Soc. Am. 15, 237-240.

McQuinn I., 1997, Metapopulations and the Atlantic Herring. Rev. Fish Biol. Fish. 7, 297-329.

Muck P., Sanchez G., 1987, The importance of mackerel and horse mackerel predation for the Peruvian anchoveta stock (a population and feeding model). In: Pauly D., Tsukayama (eds) The Peruvian anchoveta and its upwelling ecosystem: three decades of change, ICLARM Stud. Rev. 15. Manila, pp. 276-293.

Nakamura I., Inada T., Takeda M., Hatanaka H., 1986, Important fishes trawled off Patagonia. Japan Marine Fishery Resource Research Center, Tokyo.

Nesterov À.A., Chur V.N., Kolomeyko F.V., 2007, Russian fishery and researches in the Southern Pacific Ocean in 1978-1991 and 2002-2003. The jack mackerel fishery in the South Pacific Meeting, March 22, 2007, Talcahuano, Chile. Atlantic Research Institute of Marine Fisheries and Oceanography (AtlantNIRO), Kaliningrad, Russia.

Oliva M., 1999, Metazoan parasites of the jack mackerel Trachurus murphyi (Teleostei, Carangidae) in a latitudinal gradient from South America (Chile and Peru). Parasites 6, 223-230.

Ovaskainen O., Hanski I., 2004, From individual behavior to metapopulation dynamics: unifying the patchy population and classic metapopulation models. Am. Nat. 164, 364-377.

Petitgas P., Secor D.H., McQuinn I., Huse G., Lo N., 2010. Stock collapses and their recovery: mechanisms that establish and maintain life-cycle closure in space and time. ICES J.Mar. Sci. 67, 1841-1848. 
Poulin E.L. Cardenas C.E,. Hernández, I., Kornfield F., Ojeda P., 2004, Resolution of the taxonomic status of Chilean and Californian jack mackerels using mitochondrial DNA sequence. J. Fish Biol. 65, 1160-1164.

Riede K., 2004, Global register of migratory species - from global to regional scales. Final Report of the R\&D-Projet 80805081 . Federal Agency for Nature Conservation, Bonn.

Santander, H., Flores, S. 1983, Los desoves y distribución larval de cuatro especies pelágicas y sus relaciones con las variaciones del ambiente marino frente al Perú. FAO. Fish Rep. $\mathrm{N}^{\circ}$ 291, pp. 835-867.

Sepúlveda A., Cubillos L., Arcos D., 2008, Pesquerías pelágicas chilenas: una síntesis sobre la incertidumbre biológica. In: Yáñez E. (ed.). Las actividad pesquera y de acuicultura en Chile. Pontificia Universidad Católica de Valparaíso, pp. 91-107.

Sepúlveda A., Alarcón R., González C. 2007, Evaluación de la biomasa de jurel con embarcaciones de la flota pesquera 2005. Doc. Téc. Inst. Invest. Pesq. (IIP), Talcahuano 14, pp. 1-52.
Sepúlveda A., Alarcón R., Núñez S., Aguayo M., Escobar P., Vargas R., Correa M., González C., 2009, Evaluación directa del jurel con naves de la flota. Pre-Informe Final Proyecto FIP 2007-24.

Sepúlveda A., Cubillos L., Grechina A., Peña H., Vilugrón L., Hernández A., Miranda L., Serra R., Braun M., Böhm G., Galleguillos R., Montoya R., Quiñones R., 1998, Migración del jurel dentro y fuera de la ZEE de Chile. Informe final FIP9615, Instituto de Investigaciones Pesqueras, Instituto de Fomento Pesquero y Universidad de Concepción.

Serra R., 1991, Important life history aspects of the Chilean jack mackerel, Trachurus symmetricus murphyi. Invest. Pesq. 36, 67-83.

Sifeddine A., Gutiérrez,D., Ortlieb L., Boucher H., Velazco F., Field D., Vargas G., Boussafir M., Salvatteci R., Ferreira V., García M., Valdes J., Caquineau S., Mandeng Yogo M., Cetin F., Solis J., Soler P., Baumgartner T., 2008, Laminated sediments from the central Peruvian continental slope: a 500 year record of upwelling system productivity, terrestrial runoff and redox conditions. Prog. Oceanogr. 79, 190-197. 


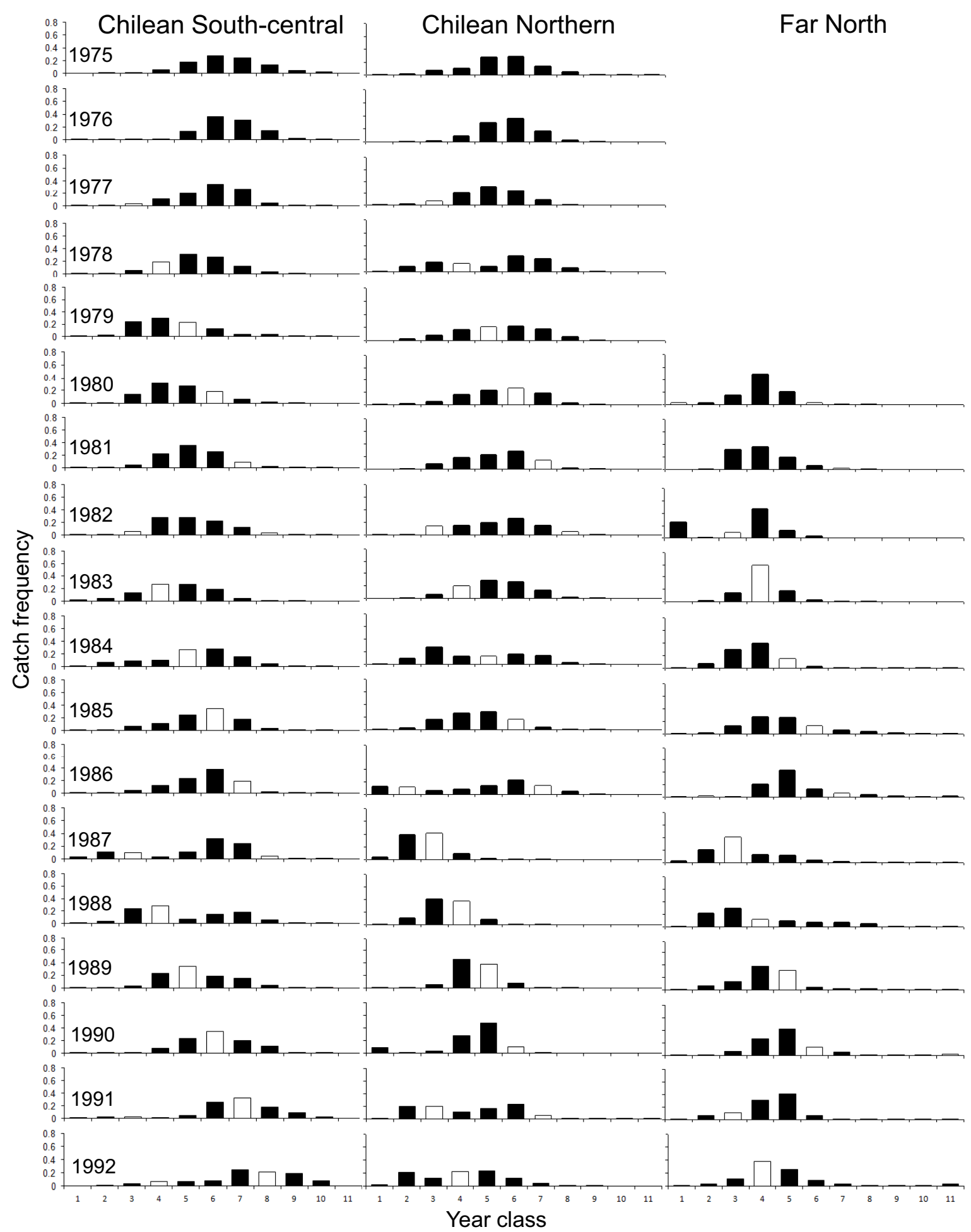

Annex. 1. Age composition of Trachurus murphyi catches for the Chilean south-central (CSC, left), the Chilean northern (NC, centre) and the Peruvian "far north" (FN, right) purse seine fisheries. Histogram in standardized proportions of abundance for year classes 3 (1st recruited class) to 13 (11th recruited class). White cohorts are those born immediately after an ENSO event that are recruited two years later. From SPRFMO (2011, www.southernpacificrfom.org). 




Annex. 1. Continued. 